\title{
PYRIDINE BASED POLYMERS. SYNTHESIS AND CHARACTERIZATION
}

\author{
M. A. PARDO, J. M. PEREZ, M. A. del VALLE, M. A. GODOY, F.R. DIAZ*
}

Pontificia Universidad Católica de Chile, Facultad de Química, Av. V. Mackenna 4860, 7820436, Macul, Santiago, Chile.

\section{ABSTRACT}

Two new conjugated polymers, poly(2,3-di(thiophen-2-yl)pyrido[2,3-b]pyrazine) and poly(2,3-di(thiophen-2-yl)pyrido[3,4-b]pyrazine), based on thiophene and pyridine rings were chemically and electrochemically synthesized and characterized by IR, UV-Vis and elemental analysis. Monomers were chemically synthesized at high yield percentages and characterized by FTIR and NMR. Polymers showed $p$ - and $n$-type doping as well as low bandgap, making them potential candidates for the development of electronic devices.

Keywords: 2,3-di(thiophen-2-yl)pyrido[2,3-b]pyrazine, 2,3-di(thiophen-2-yl)pyrido[3,4-b]pyrazine, poly(2,3-di(thiophen-2-yl)pyrido[2,3-b]pyrazine) and poly(2,3-di(thiophen-2-yl)pyrido[3,4-b]pyrazine).

\section{INTRODUCTION}

Thiophene based polymers have been widely investigated for the development of new technologic applications ${ }^{1,2}$. On the other hand, thanks to its structural diversity, nitrogen containing heterocycles have also attracted considerable interest in recent years due to their unique properties ${ }^{3-5}$. Thiophene and quinoxaline copolymers have been employed as electronic carriers in electroluminescent devices ${ }^{6}$ and as material for organic light-emitting devices 7 , among others.

Likewise, thiophene combined with other hetero-aromatic rings such as pyrrole, pyridine, pyrazine, quinoxaline and aniline has been studied in order to obtain a stable compound that has low enough reduction potential to be used instead of fullerenes as $n$-type semiconductor in organic solar cells ${ }^{8,9}$.
In this context, our research group has developed different materials based on thiophene rings, and nitrogen containing rings in its structure to be employed for the development of photovoltaic devices ${ }^{10,11}$, e.g. the synthesis of 2,3-di(thiophen-2-yl)quinoxaline monomer was achieved using a simple method, with $98 \%$ yield ${ }^{12}$. Other authors have found new synthetic route for the synthesis of this compound, using Grignard reagents with a $90 \%$ yield ${ }^{13}$. Moreover, it has also been reported the synthesis of pyrazine derivatives with antimicrobial activity, with yields close to $40 \%{ }^{14}$.

This work is the continuation of our study concerning to conjugated pirazine-like structures with the insertion of a new nitrogen atom into the monomer, from pyridine-based monomers synthesis, aimed to obtaining a better performance using 2,3-di(thiophen-2-yl)quinoxaline as reference, Fig. 1.<smiles>[2H]c1c(C)c(C)c([B])c2nc(-c3sc([B])c(C)c3C)c(-c3scc(C)c3C)nc12</smiles>

TQ<smiles>Cc1cc2nc(-c3sc(C)c(C)c3C)c(-c3sc(C)c(C)c3C)nc2nc1C</smiles>

2,3BP

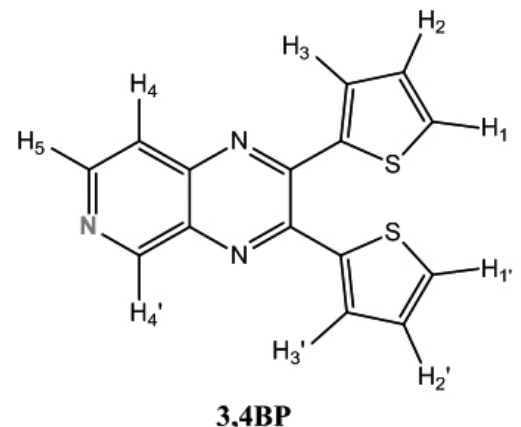

3,4BP

Figure 1. a) 2,3-di(thiophen-2-yl)quinoxaline (TQ), b) 2,3-di(thiophen-2-yl)pyrido[2,3-b]pyrazine, c) 2,3-di(thiophen-2-yl)pyrido[3,4-b]pyrazine.

\section{EXPERIMENTAL}

\section{Materials}

All starting materials and reagents used were: acetonitrile (98\%, Merck); ethyl acetate for liquid chromatography ( $99.8 \%$, Merck); chloroform (99.4\%,Merck), anhydrous ferric chloride (Sigma); iodine for analysis (99.8\%, Merck), ethanol (98\%, Merck), o-phenylenediamine (99\%, Aldrich Chemistry); silica gel 60 (Merck); 2,2'-thenil (98\%, Aldrich Chemistry); 2,3-diaminopiridine (Merck); 3,4-diaminopiridine (Merck); $\mathrm{HCl}$ concentrated ( $37 \%$, Merck). All reagents were used without further purification.

\section{Measurements}

${ }^{1} \mathrm{H}$ NMR spectra were collected on a Bruker 400 spectrometer using chloroform- $d$ as solvent and TMS as internal standard. FT-IR spectra were recorded on a Brucker Vector-22 spectrophotometer using $\mathrm{KBr}$ pellets. Elemental analysis was performed on a Fison 1108 microanalyser. UV-VIS spectra were obtained on a Analytik Jena Specord 40, using acetonitrile and chloroform as solvent. The determination of melting point was carried out on a Stuart Scientific Melting Point Apparatus (SMP3). Potentiodynamic and potentiostatic measurements were acquired using a Voltammetric Analyzer CV$50 \mathrm{~W}$ by BAS; electrochemical experiments were performed in a conventional three electrodes cell, using anhydrous acetonitrile as solvent, and $0.1 \mathrm{~mol} \cdot \mathrm{L}^{-1}$ tetramethylammonium hexafluorophosphate $\left(\mathrm{NH}_{4}\left(\mathrm{CH}_{3}\right)_{4} \mathrm{PF}_{6}\right.$, supplied by Aldrich) as supporting electrolyte. It was employed a $\mathrm{Ag} \mid \mathrm{AgCl}$ electrode as reference in tetramethylammonium chloride with potential adjusted to that of SCE. The working electrodes were platinum disc $\left(0.1 \mathrm{~cm}^{2}\right.$ of geometrical area).

As counter electrode it was used a Pt gauze of large geometrical area, separated from the working electrode compartment by a fine frit glass. Prior to all the experiments, solutions were purged with high purity argon and it was maintained over the solution during the measurements. The conductivity of the polymer was measured with a conductance meter Elchema, model CM-508, by the four probe method. All experiments were carried out at room temperature 
$\left(20^{\circ} \mathrm{C}\right)$

From UV-Vis spectra of the doped polymers the forbidden energy band was calculated, following the Born-Einstein energy relationship ${ }^{6}$. The frontier orbital energy HOMO $\left(\mathrm{E}_{\text {номо }}\right)$ correlates linearly with the oxidation onset potential (Eon)ox and it was calculated directly from the voltammograms ${ }^{10}$.

Synthesis of monomers

Synthesis of 2,3-di(thiophen-2-yl)quinoxaline (TQ)

The synthetic route of 2,3-di(thiophen-2-yl)quinoxaline was performed from the procedure previously reported, with $93 \%$ yield ${ }^{12}$. A mixture of 2,2'-thenil (200 mg; $0.9 \mathrm{mmol})$ and $o$-phenylenediamine $(291 \mathrm{mg} ; 2.7 \mathrm{mmol})$ in ethanol was refluxed for $3 \mathrm{~h}$ and cooled to room temperature ${ }^{12}$. Elemental analysis, found \% (calculated \%): C, 65.23 (65.30); H, 3.54 (3.40); N, 9.58 (9.52); S, 21.65 (21.77). Melting point: $146.1-146.6^{\circ} \mathrm{C}$. FTIR $\left(\mathrm{cm}^{-1}\right)$ : 3488.7 , 3075.5, 1515.9, 1450.9, 1417.5, 836.9, 762.5. ${ }^{1} \mathrm{H}-\mathrm{NMR}(\mathrm{CDCI}, 400 \mathrm{MHz}$, ppm): 8.01-8.05 (m, 2H, 4,4'-H); 7.75-7.70 (m, 2H, 5,5'- H); 7.51-7.49 (m, $\left.2 \mathrm{H}, 3,3^{\prime}-\mathrm{H}\right)$; 7.27-7.23 (m, 2H, 1,1'-H); 7,06-7,02 (m, 2H, 2,2'-H). UV-Vis (nm): 257, 274 and 382.

Synthesis of 2,3-di(thiophen-2-yl)pyrido[2,3-b]pyrazine (2,3BP)

A mixture of 2,2 '-thenil (500 $\mathrm{mg} ; 2.26 \mathrm{mmol}$ ) and 2,3-diaminepyridine $(1.4 \mathrm{~g}, 0.128 \mathrm{~mol})$ in ethanol was refluxed until a yellow solid was observed. The monomer was purified using a silica gel column and hexane : ethyl acetate mixture as eluent. Product was obtained in a $75 \%$ yield. Elemental analysis, found \% (calculated \%): C, 60.85 (60.99); N, 14.29 (14.23); H, 2.54 (3.07); S, 18.98 (21.71). Melting point: $165.3-165.5^{\circ} \mathrm{C}$. FT-IR $\left(\mathrm{cm}^{-1}\right) 3430.8,3088.4$, 1516.3, 1416.7, 845.8, 714.9. $\left.{ }^{1} \mathrm{H}-\mathrm{NMR}\left(\mathrm{CDCI}_{3}\right) 400 \mathrm{MHz}, \mathrm{ppm}\right): 9.5$ (s, $1 \mathrm{H}$, 6); $8.79(\mathrm{~s}, 1 \mathrm{H}, 4) ; 7.91-7.89(\mathrm{~d}, 1 \mathrm{H}, 5) ; 7.60-7.57\left(\mathrm{~m}, 2 \mathrm{H}, 1,1^{\prime}\right) ; 7.38-7.37(\mathrm{~m}$, $\left.2 \mathrm{H}, 3,3^{\prime}\right) ; 7.10-7.06\left(\mathrm{~m}, 2 \mathrm{H}, 2,2^{\prime}\right)$. UV-Vis (nm): 253, 286 and 391.

Synthesis of 2,3-di(thiophen-2-yl)pyrido[3,4-b]pyrazine (3,4BP)

$3,4 \mathrm{BP}$ was synthetized following the same procedure described above. The product was obtained in a $81 \%$ of yield. Melting point: $163.9-164.8^{\circ} \mathrm{C}$. FT-IR $\left(\mathrm{cm}^{-1}\right) 3447.8,3101.7,1596.8,1520.1-1410.7,829.7,728.7 .{ }^{1} \mathrm{H}-\mathrm{NMR}\left(\mathrm{CDCI}_{3}\right)$ $400 \mathrm{MHz}, \mathrm{ppm}$ ): 9.39 (s, 1H, 6); 8.68-8.67 (d, 1H, 4); 7.89-7.78 (d, 1H, 5); 7.49-7.47 (t, 2H, 1,1' ); 7.28-7.27 (m, 2H, 3,3'); 7.0-6.96 (m, 2H, 2,2'). UV-Vis (nm): 253, 283 and 390.

\section{Chemical Polymerization}

All of the polymers were synthesized in chloroform using methodology previously reported ${ }^{12}$. The corresponding polymers were named PTQ, P2,3BT and $\mathrm{P} 3,4 \mathrm{BT}$, respectively. Each monomer and $\mathrm{FeCl}_{3}$ were dissolved in chloroform to achieve a molar ratio of $\mathrm{FeCl}_{3}$ to monomer (4:1), while it was being stirred at room temperature under a $\mathrm{N}_{2}$ flow during $72 \mathrm{~h}$. The resulting polymer was washed with water and ethanol, and the precipitated is dried in a vacuum owen. The resulting polymers were compacted into pellets and weighed. These pellets were then put into open weighing bottles, which were placed in a small desiccator protected from light and charged with ground iodine powder. Iodine uptake by the polymers was followed by mass differential.

Doped polymers were dissolved in DMSO to obtain UV-Vis absorption spectra. This enabled the forbidden energy band of each material to be worked out.

Synthesis of poly(2,3-di(2-thenil)quinoxaline) (PTQ)

PTQ was synthesized by following the same procedure explains above. After purification a brown-red solid was obtained with a yield of $34 \%$. Elemental analysis, found \% (calculated \%): C, $54.71(66,28)$; N, $14.29(9,52)$; H, 1.82 (3,42); S, 17.15 (21.78). FT-IR $\left(\mathrm{cm}^{-1}\right) 3441.1,3093.9$, 1423.2, 1418, 851.9, 763.4. UV-Vis (nm): 254, 291, 384.

\section{Synthesis of poly(2,3-di(thiophen-2-yl)pyrido[2,3-b]pyrazine)} (P2,3BP)

P2,3BP was synthesized following the same procedure explains for chemical polymerization. Additionally the solid was washed twice with ethyl acetate. After purification a brown-red solid was obtained with a yield of 31 $\%$. Elemental analysis: found \% (calculated \%): C, 54.71 (60.99); N, 10.91 (14.23); H, 1.9 (3.07); S, 15.31 (21.71). FT-IR $\left(\mathrm{cm}^{-1}\right): 3423.9$, 3084.6, 1520, 852.3, 715.3. UV-Vis (nm): 260, 394.

\section{Synthesis of poly(2,3-di(thiophen-2-yl)pyrido[3,4-b]pyrazine)} (P3,4BP)

P3,4BP was synthesized by the same procedure explains for chemical polymerization, and the solid was washed with acetonitrile. After purification a polymer as brow-red solid was obtained with a yield of $38 \%$. Elemental analysis: found \% (calculated \%): C, 49.27 (60.99); N, 10.91 (14.23); H, 1.9 (3.07); S, 15.31 (21.71). FT-IR ( $\left.\mathrm{cm}^{-1}\right)$ : 3430.1, 3100.4, 3074.6, 1598, 1520.4, 827.8, 729.8. UV-Vis (nm): 257, 290 and 395.

\section{Electrochemical polymerization}

Electrochemical polymerizations were carried out following the procedure previously reported ${ }^{12}$.

\section{Electropolymerization of 2,3-di(thiophen-2-yl)quinoxaline}

The monomer electropolymerization was carried out by 20 successive voltammetric scans. It was performed in the following conditions: $5.7 \cdot 10^{-3}$ $\mathrm{mol} \cdot \mathrm{L}^{-1}$ monomer, $2.2 \cdot 10^{-2} \mathrm{~mol} \cdot \mathrm{L}^{-1}$ supporting electrolyte $\left(\mathrm{NH}_{4}\left(\mathrm{CH}_{3}\right)_{4} \mathrm{PF}_{6}\right)$ in anhydrous acetonitrile. The optimal potential range to polymerize was -0.50 to $1.80 \mathrm{~V}$.

Electropolymerization of 2,3-di(thiophen-2-yl)pyrido[2,3-b]pyrazine

$\mathrm{P} 2,3 \mathrm{BP}$ electrosynthesis was carried out by 30 successive voltammetric scans. It was performed in the following conditions: $5.7 \cdot 10^{-3} \mathrm{~mol} \cdot \mathrm{L}^{-1}$ monomer, $2.2 \cdot 10^{-2} \mathrm{~mol} \cdot \mathrm{L}^{-1}$ supporting electrolyte $\left(\mathrm{NH}_{4}\left(\mathrm{CH}_{3}\right)_{4} \mathrm{PF}_{6}\right)$ in anhydrous acetonitrile. The optimal potential range to polymerize was $-1,0$ to $1.5 \mathrm{~V}$.

Electropolymerization of 2,3-di(thiophen-2-yl)pyrido[3,4-b]pyrazine

P3,4BP electrosynthesis was carried out by 30 successive voltammetric scans. It was performed in the following conditions: $5.7 \cdot 10^{-3} \mathrm{~mol} \cdot \mathrm{L}^{-1}$ monomer, $2.2 \cdot 10^{-2} \mathrm{~mol} \cdot \mathrm{L}^{-1}$ supporting electrolyte $\left(\mathrm{NH}_{4}\left(\mathrm{CH}_{3}\right)_{4} \mathrm{PF}_{6}\right)$ in anhydrous acetonitrile. The optimal potential range to polymerize was -1.0 to $1.5 \mathrm{~V}$.

\section{RESULTS AND DISCUSSION}

\section{Synthesis and characterization of monomers}

The synthetic route of all monomers was performed from the procedure previously reported ${ }^{12}$. After $3 \mathrm{~h}$ all compounds were quantitatively converted to product, without by-products.

\section{Chemical polymerization and characterization}

All polymerizations afforded low reaction yields, $c a .30 \%$, considering just the insoluble fraction or higher molecular weight. Elemental analysis showed significant variation in the experimental and theoretical percentages, considering that the polymer in its oxidized state has $\mathrm{Fe}^{2+}$ ions trapped in its structure (2-3 atoms of Fe per monomer) which justifies the lower concentration of elements in the actual sample.

The solution UV-Vis absorption spectra for all polymers showed two or three distinct absorption bands: two or a single band around 250-300 nm can be assigned to the $\pi-\pi^{*}$ transition while a long-wavelength absorption peaks, around $390 \mathrm{~nm}$, can be attributed to intramolecular charge transfer between thiophene rings and acceptor moieties ${ }^{15,16}$. The polymers absorption spectra are red shifted compared to the corresponding monomers spectra (Figure 2), which can be attributed to an increase in the chain length ${ }^{17}$.

From UV-Vis spectrum of the doped polymers the forbidden energy band was calculated, following the Born-Einstein energy relationship ${ }^{6}$. Likewise, the conductivity of doped polymers was measured; an increase of up to 6 orders of magnitude compared to the neutral polymers was observed. Comparison of $\mathrm{P} 2,3 \mathrm{BP}$ and $\mathrm{P} 3,4 \mathrm{BP}$ with PTQ showed a conductivity increase of about 10 times, which is probably related to the insertion of the nitrogen atom into the aromatic ring that would confer higher planarity to the polymeric chain, generating thus improved charge transfer between parallel chains, Table 1.

Table 1. Conductivity of the synthesized species and $\mathrm{E}_{\mathrm{g}}$ of the doped polymers.

\begin{tabular}{|c|c|c|c|}
\hline \multirow{2}{*}{ polymer } & \multicolumn{2}{|c|}{ conductivity $\left(\mathbf{S}^{-\mathbf{c m}^{-1}}\right)$} & \multirow{2}{*}{ bandgap energy $(\mathbf{e V})$} \\
\cline { 2 - 3 } & monomer & polymer & \\
\hline PTQ & $2.0 \cdot 10^{-5}$ & $2.4 \cdot 10^{-5}$ & 3.05 \\
\hline P2,3BP & $3.0 \cdot 10^{-10}$ & $1.1 \cdot 10^{-4}$ & 3.82 \\
\hline P3,4BP & $3.0 \cdot 10^{-10}$ & $0.7 \cdot 10^{-4}$ & 3.33 \\
\hline
\end{tabular}




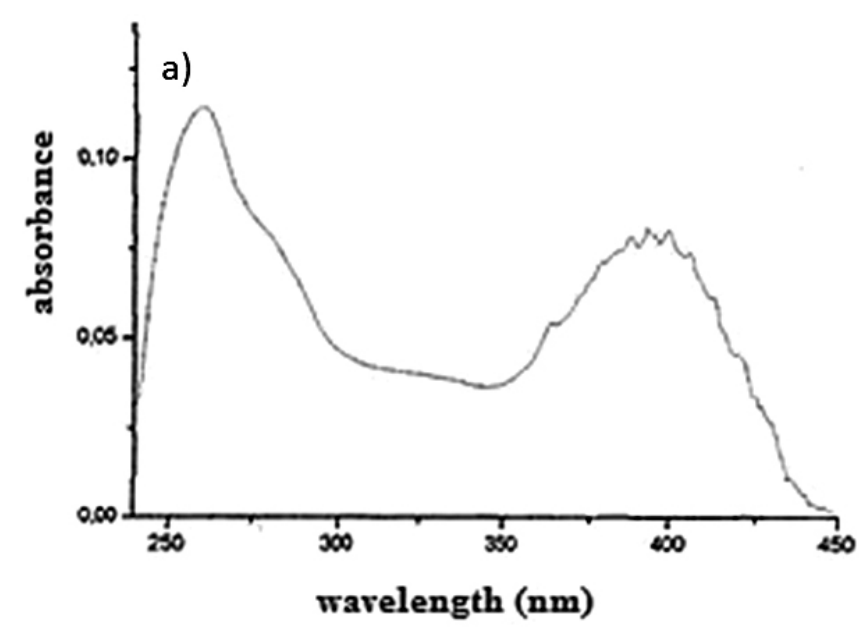

Figure 2. a) $\mathrm{P} 2,3 \mathrm{BP}$ UV-Vis absorption spectrum; b) $\mathrm{P} 2,3 \mathrm{BP}$ IR spectrum.

\section{Electrochemical polymerization and characterization}

Figure 3 shows the potentiodynamic $\mathrm{j} / \mathrm{E}$ profiles during the first 20 voltammetric cycles on Pt of each monomer in acetonitrile. Table 2 shows the oxidation potential of all monomers on Pt. In TQ potentiodynamic i/ E profile it can be observed that the oxidation potential of the electroactive species (near $1.4 \mathrm{~V} v s \mathrm{SCE}$ ) shifts continuously to smaller values when the number of cycles increases, until it stabilized near $1,3 \mathrm{~V}$ while the corresponding reduction peak remain practically constant in $0.35 \mathrm{~V}$. This behavior was previously reported under similar experimental conditions. Then, it could be inferred that the profile observed in this potential range can be assigned to the polymerization through

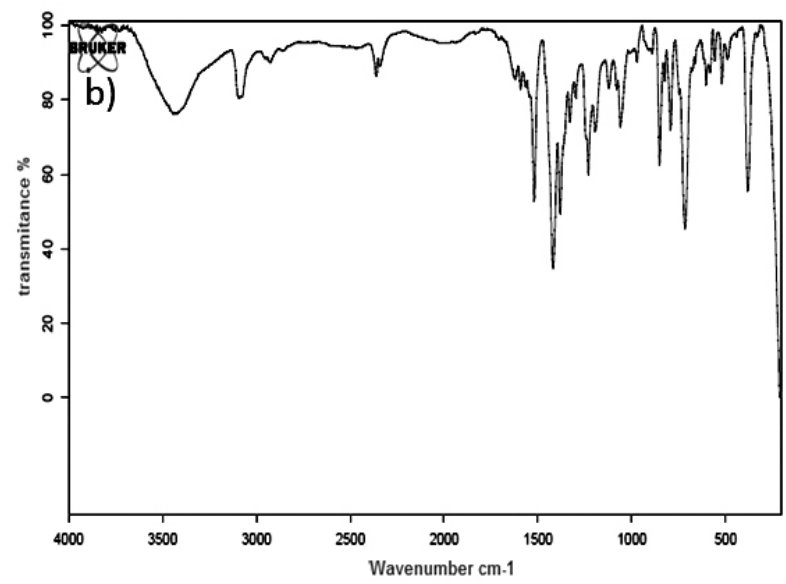

the oxidation of thiophene rings in the molecule ${ }^{12}$. It is well know that the fact that potential gives less positive values during successive voltammetric scans is attributed to a high conjugation due to the increase of the chain length, as the oligomerization and polymerization processes take place. The oxidation charge is bigger than that of the corresponding reduction peak because in the first are included polymerization and $p$-doping charges while the reduction process involves only the $p$-undoping charge. The other monomers present the same behavior showing oxidation potentials near 1.1 and 1.2 for $\mathrm{P} 2,3 \mathrm{BP}$ and $\mathrm{P} 3,4 \mathrm{BP}$, respectively (Table 2).
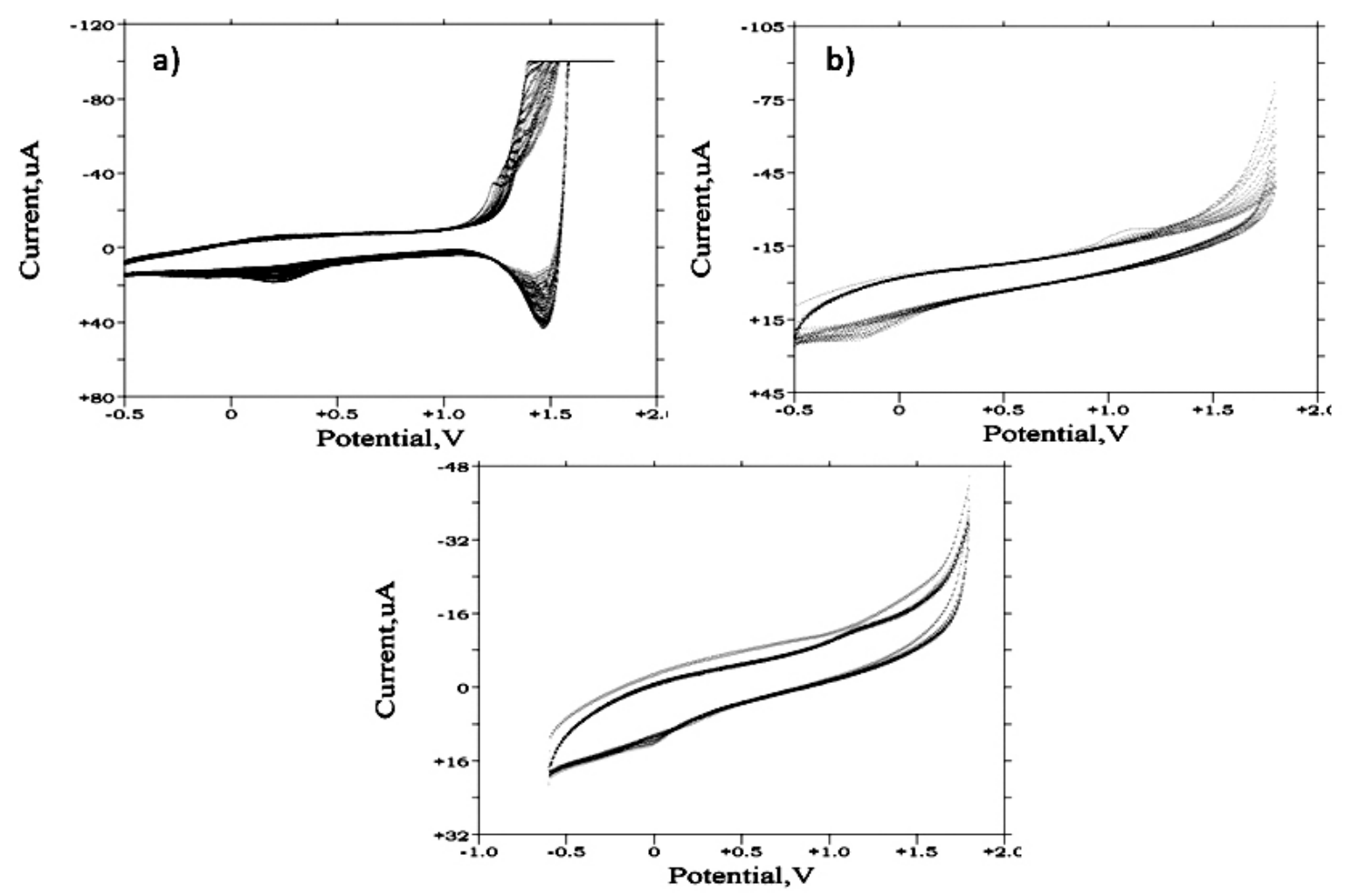

Figure 3. Potentiodynamic i/E profiles in acetonitrile: a) 2,3-di(2-thiophen)quinoxaline; b) 2,3-di(2-thiophenyl)pyrido[2,3-b]pyrazine; c) potentiodynamic 2,3-di(2-thiophenyl)pyrido[3,4-b]pyrazine. 
Table 2. Electrical properties of the synthesized polymers.

\begin{tabular}{|c|c|c|c|c|}
\hline polymer & $\begin{array}{c}\text { reduction } \\
\text { potential (eV) }\end{array}$ & $\begin{array}{c}\text { oxidation } \\
\text { potential (eV) }\end{array}$ & $\begin{array}{c}\text { HOMO } \\
(\mathbf{e V})\end{array}$ & $\begin{array}{c}\text { LUMO } \\
\mathbf{( e V )}\end{array}$ \\
\hline PTQ & 0.35 & 1,35 & -5.8 & -2.75 \\
\hline P2,3BP & -0.2 & 1.10 & -5.5 & -1.68 \\
\hline P3,4BP & -0.9 & 1.20 & -5.6 & -2.27 \\
\hline
\end{tabular}

\section{CONCLUSIONS}

The synthesis of the proposed monomers was possible, following the same methodology previously implemented, with very good results. A new series of polymers was synthesized and characterized by FT-IR and NMR. Electrochemical characterization demonstrates that he polymers showed $p$-and $n$-doping and low bandgap $(\sim 1.00 \mathrm{eV})$, making those prospective candidates for the development of electronic devices.

\section{DEDICATION}

This work is dedicated to Dr. Luis Núñez Vergara (RIP), to whom we express our sincere admiration and respect.

\section{ACKNOWLEDGEMENTS}

The authors acknowledge financial support from CONICYT through FONDECYT project 1120055.

\section{REFERENCES}

1. G. Barbarella, M. Melucci, G. Sotgiu, Advanced Materials 17, 1581, (2005).
2. A. Mishra, C. Ma, P. Bauerle, Chemical Reviews 109, 1141, (2009).

3. E. Ortega, F. Armijo, I. Jessop, M. A. del Valle, F.R. Díaz, Journal of the Chilean Chemical Society 58, 1959, (2013).

4. E. Turac, E. Sahmetlioglu, L. Toppare, H. Yuruk, Journal of Applied Polymer Science 120, 1713, (2011).

5. C. O. Sanchez, A. Isla, C. Bustos, F. R. Díaz, N. Gatica, Journal of the Chilean Chemical Society 55, 233, (2010).

6. Y. Cui, X. Zhang, S. A. Jenekhe, Macromolecules 32, 3824, (1999).

7. P. Wang, Z. Xie, Z. Hong, J. Tang, O. Wong, C. Lee, N. Wong, S. Lee, Journal of Materials Chemistry 13, 1894, (2003).

8. Y. Cheng, S. Yang, C. Hsu, Chemical Reviews 109, 5868, (2009).

9. J. C. Bernède, Journal of the Chilean Chemical Society 53, 1549, (2008).

10. I. A. Jessop, P. P. Zamora, F. R. Diaz, M. A. del Valle, A. Leiva, L. Cattin, M. Makha, J. C. Bernède, International Journal of Electrochemical Science 7, 9502, (2012).

11. P. P. Zamora, M. B. Camarada, I. A. Jessop, F. R. Diaz, M. A. del Valle, L. Cattin, G. Louarn, J. C. Bernède, International Journal of Electrochemical Science 7, 8276, (2012).

12. F. R. Diaz, del M. A. del Valle, C. Núñez, A. Godoy, J. L. Mondaca, A. Toro-Labbé, J. C. Bernède, Polymer Bulletin 56, 155, (2006).

13. T. Cai, Y. Zhou, E. Wang, S. Hellström, F. Zhang, S. Xu, O. Inganäs, M. R. Andersson, Solar Energy Materials and Solar Cells 94, 1275, (2010).

14. B. Mathew, S. Srivastava, L. J. Ross, W. J. Suling, E. L. White, L. K. Woolhiser, A. J. Lenaerts, R. C. Reynolds, Bioorganic and Medicinal Chemistry 19, 7120 (2011).

15. T. Cai, Y. Zhou, E. Wang, S. Hellström, F. Zhang, S. Xu, O. Inganäs, M. R. Andersson, Solar Energy Materials and Solar Cells 94, 1275 (2010).

16. Y. Zhu, R. D. Champion, S. A. Jenekhe, Macromolecules 39, 8712, (2006).

17. K.G. Jespersen, W.J. Beenken, Y. Zaushitsyn, A. Yartsev, M. Andersson, T. Pullerits, V. Sundström, The Journal of Chemical Physics 121, 12613, (2004). 